\title{
STUDY OF BMI AND BODY FAT\% IN ADOLESCENT BOYS
}

\author{
Biswabara Rout ${ }^{1}$, Snigdha Prava Mishra ${ }^{2}$, Tapas Ranjan Behera *3. \\ ${ }^{1}$ Assistant Professor, Department of Physiology, SCB Medical College, Cuttack, Odisha, India. \\ ${ }^{2}$ Associate Professor, Department of Physiology, MKCG Medical College, Berhampur, Odisha, India. \\ ${ }^{* 3}$ Assistant Professor, Department of Community Medicine, SCB Medical College, Cuttack, Odisha, \\ India.
}

\section{ABSTRACT}

Background: The increasing prevalence of overweight and obesity has raised concerns regarding the importance of different techniques, which are used to assess body growth composition. There are many grave health risk of being overweight and obese. Recently childhood obesity has increased dramatically. BMI has been used for long to assess health and obesity. There are studies in India on prevalence of childhood obesity which are based on BMI. Very few studies have been conducted on school children of Odisha and none of them have taken body fat $\%$ in to consideration. Our study focuses on the prevalence of obesity in boys of adolescent age group of southern urban Odisha.

Materials and Methods: In this cross sectional study we have selected the subjects randomly from different schools of Berhampur town, Odisha. Total number of subjects were 348 . Anthropometric parameters \& BF \% were measured. Body fat \% in different range of BMI was studied.

Result: Out of 348 boys $38.5 \%$ were having normal BMI, $54.02 \%$ less than normal \& $7.47 \%$ have more than normal BMI. Out of total number of subjects, 176 (50.57\%) have less than $20 \%$ BF, $172(49.42 \%)$ have more than $20 \%$ BF.

Conclusion: Almost half of the study group showed BF \% more than normal. The excessive BF \% observed among the children in this study and may have its impact on their health and fitness.

KEY WORDS: School Children, Obesity, Overweight, BMI, BF \%.

Address for correspondence: Dr Tapas Ranjan Behera, Assistant Professor, Department of Community Medicine, SCB Medical College, Cuttack, Odisha, India.

E-Mail: tapas4behera@gmail.com

\begin{tabular}{|l|l|}
\hline \multicolumn{3}{c|}{ Access this Article online } \\
\hline Quick Response code & International Journal of Physiotherapy and Research \\
ISSN 2321- 1822
\end{tabular}

INTRODUCTION

The World Health Organization (WHO) describes overweight and obesity as today's most important public health problem, which is escalating as a global pandemic. Obesity is a being long considered as a problem of developed countries, now it has increasingly recognized as a significant problem in developing countries, countries undergoing economic transition and is no more considered as a future tense for them [1].
Prevalence of childhood obesity has increased dramatically since 1990 [2]. A recently published analysis of 450 nationally representative cross sectional surveys from 144 countries showed that 43 million children ( 35 million in developing countries) are estimated to be overweight and obese, while 92 million are at risk of overweight [3]. The grave health risk of being overweight include hypertension, hypercholesterolemia, sleep disorder, gall bladder disease, 
increase possibilities of type 2 diabetes and back and joint pain. India is now in epidemiological polarization where at one hand we are facing challenges to combat the under-nutrition, on the other hand over-nutrition starts showing its effect [4].

It is important to have valid and reliable tools to assess the body growth and composition. Techniques that accurately depict body fat percentage (BF\%) can be used as a tool to evaluate an individual's weight loss or gain over a period of time. While direct assessment of fat mass may be a better index of obesity, routine evaluation of regional fat distribution on a wide scale requires methods that are simpler than dual energy $X$ ray absorptiometry, computed tomography, or magnetic resonance imaging due to their various limitations. Body impedance analysis is a relatively simple but reliable, quick, and non invasive method, and it is widely used to evaluate body composition. However, anthropometry still remains the most widely used method for clinical and epidemiological purposes [5], out of which BMI is the parameter most frequently used for the screening of overweight and obesity because it is easy to determine and it tends to correlate well with body fat. On the other hand, there are also data indicating that $\mathrm{BMI}$ provides misleading results concerning body fat content in different ethnic groups $[5,6]$. Since BMI depends on both weight and height, it is expected to depend on both genetic and environmental factors.

BMI has been used for long to assess health and obesity. But it has important limitation of not distinguishing between body fat and fat free mass [4]. This limitation has led to search of alternative method of estimation of total body fat. Bioelectric impedance analysis (BIA), a simple, convenient and inexpensive method for assessing adiposity has gained popularity in last few years. (5) Childhood obesity increases the risk of obesity in adults. Present study was an attempt to explore obesity and overweight prevalence among the adolescent school boys in suburban areas of Berhampur city, Odisha, India.

\section{MATERIALS AND METHODS}

This study was conducted in urban area of
Berhampur, District Ganjam, Odisha and the it was conducted between March 2015 and May 2015. It was a cross sectional School based study on 348 School Children (Boys) within age group of 12-16 years.

Inclusion and exclusion criteria: Study subjects who were present on the day of visit to the different schools and had given informed consent with prior consent of the Class teachers and permission of the principals were included in the study. Subjects with Water electrolyte imbalance (oedema or ascites), Skin abnormalities (pachydermia secondary to hypothyroidism) abnormal geometry (amputation, limb atrophy or BMI more than $38 \mathrm{~kg} / \mathrm{m}$ square) were excluded from the study.

Ethical consideration: The permission and ethical clearance for the study were obtained from the Institutional Ethics Committee of MKCG Medical College, Berhampur, Odisha (No.-254/ Chairman-IEC, MKCG Medical College, Brahmapur-4)

Methodology: Before the study, the participants were explained about the procedure and the permission of the principal and consent of the teachers were also taken. The purpose and process of the study was explained to all the boys and teacher. Study included 348 boys, randomly selected within the age group 12-16 years.

Data were collected on a predesigned, pretested, and semi structured schedule that included the characteristics of respondents such as age, height, weight, BMI $\left(\mathrm{kg} / \mathrm{m}^{2}\right)$, Body Fat $\%$. Anthropometric measurements like height (measured up to the nearest $0.1 \mathrm{~cm}$ by fiberoptic tape) and body weight (measured without shoe with minimal clothing using digital weighing machine up to the nearest $0.5 \mathrm{~kg}$ ) were taken, Body Fat \% was recorded by Omron body fat monitor (HBF-306).

Body Fat \% was measured using a commercially available bioelectric impedance analyzer (HBF 306, Omron Health Care Co., Kyoto, Japan). Prior information about the protocol for the Body Fat $\%$ measurement such as refraining from food and drink for at least $6 \mathrm{hr}$ and voiding urine before measurement was given to subjects a day before the scheduled program by the investigators. Subjects were requested to moisten the 
palms with a wet towel before taking the measurement. The study subjects were asked to stand on the flat surface and gently grasp the two handgrips with arms held straight forward. BF\% $>20 \%$ in boys was taken as high.

\section{RESULTS}

A total of 348 boys in the age group 12-16 years were selected randomly from different schools of Berhampur in urban area for the study.

Table 1: Mean height, weight, BMI, \%BF in the study population.

\begin{tabular}{|c|c|c|c|c|}
\hline $\begin{array}{c}\text { Total no of study } \\
\text { subjects } \\
\text { (n= 348) }\end{array}$ & Height (cm) & Weight (kg) & BMI & $\begin{array}{c}\text { Body Fat } \\
\%\end{array}$ \\
\hline Mean & 151.06 & 42.47 & 18.41 & 20.32 \\
\hline SD & 8.457 & 10.692 & 3.686 & 5.802 \\
\hline
\end{tabular}

The mean height of the study boys was 151.06 $\pm 8.4 \mathrm{~cm}$, whereas the mean weight was 42.47 $\pm 10.6 \mathrm{~kg}$. The mean BMI calculated among these boys was found to be $18.41 \pm 3.68 \mathrm{~kg} / \mathrm{m}^{2}$. The mean \% Body Fat calculated by Omron body fat monitor (HBF-306) was $20.32 \pm 5.8 \%$.

Table 2: Body Fat percentage in different range of BMI.

\begin{tabular}{|c|c|c|c|}
\hline $\begin{array}{c}\text { BMI } \\
\left(\mathbf{k g} / \mathbf{m}^{2}\right)\end{array}$ & Body Fat \% (<20) & Body Fat \% (>20) & Total \\
\hline $\mathbf{2 1 8}$ & $144(41.37 \%)$ & $44(12.64 \%)$ & 188 \\
\hline $\mathbf{1 8 - 2 4 . 9}$ & $32(9.19 \%)$ & $102(29.31 \%)$ & 134 \\
\hline $\mathbf{2 5 - 2 9 . 9}$ & 0 & $22(6.32 \%)$ & 22 \\
\hline$>\mathbf{3 0}$ & 0 & $4(1.14 \%)$ & 4 \\
\hline Total & $176(50.56 \%)$ & $172(49.41 \%)$ & 348 \\
\hline
\end{tabular}

Out of the total 348 students, BMI of 134 (38.5\%) was within normal range. BMI was less than normal in 188 (54.02\%) and more than normal in $26(7.4 \%)$ boys. In the higher BMI group, 22 (6.26\%) were overweight and $4(1.13 \%)$ were obese. The difference of percentage of body fat among these two BMI groups (Normal BMI vs Pre-Obese) of these school boys was found to be statistically significant $(p<0.05)$.

Among the normal BMI group $\left(18-24.99 \mathrm{~kg} / \mathrm{m}^{2}\right)$, 102 (29.31\%) students had BF\% more than normal range. Whereas among the low $\mathrm{BMI}$ group $\left(18 \mathrm{~kg} / \mathrm{m}^{2}\right), 44(12.64 \%)$ students showed BF\% in higher range. The difference of percentage of body fat among these two BMI groups (Normal BMI vs below Normal BMI) of these school boys was found to be statistically significant $(p<0.05)$.

However the difference of percentage of body fat among other two BMI groups (Normal BMI vs Obese) of these school boys was not found to be statistically significant $(p>0.05)$.

\section{DISCUSSION}

In the present study we studied BMI \& BF\% in school boys of sub-urban areas of Berhampur town of southern Odisha in the age group of 12- 16 yrs. The prevalence of overweight \& obesity in our study was $7.46 \%$. Previous such studies in Odisha by S. Pati et al [8] in Cuttack city of Northern Odisha shows the prevalence to be $11.9 \%$, whereas A. K. Mishra et al [4] in Sambalpur district of Western Odisha found 9\% as prevalence of overweight \& obesity among school boys. Our study showed that $29.31 \%$ boys with normal BMI $\left(18-14.9 \mathrm{Kg} / \mathrm{m}^{2}\right)$ have their BF $\%$ in the higher range $(>20)$. Similarly $12.64 \%$ boys with less than normal BMI $\left(<18 \mathrm{Kg} / \mathrm{m}^{2}\right)$ range have their $\mathrm{BF} \%$ in the higher range $(>20)$. In a similar type of study by R. Khadgawat et al [2] among apparently healthy School Children from Delhi found the mean BF \% among 825 boys to be $23.5 \%$. In our study the mean $\mathrm{BF} \%$ was found to be $20.32 \%$. Indian children show consistently higher rise in Body Fat $\%$ with age as compared to others. The measurement of body fat by direct method is better than assessing "fatness" with indirect methods, like BMI. However, lack of clear cut-offs for defining excess body fat makes their use limited in both research and clinical practice. Various factors responsible for increasing Body Fat \% among adolescent boys are rapid economic growth, lifestyle and behaviour alteration, unhealthy eating habits, physical inactivity, sedentary life style, habits like more time in television watching, computer games, internet, overemphasis on academic excellence etc. [10].

Limitation of the study: Our study did not include waist hip ratio as a parameter for assessment of overweight and obesity, we have taken only boys as study population.

\section{CONCLUSION}

So the present study focusses on the fact that only BMI cannot be taken into consideration to 
find out obesity as it is not able to distinguish between body fat and fat free mass. Percentage of Body Fat is very important as most of the weight related problems are due to the higher Body Fat \%. All most all lifestyle modification like compulsory physical activity, discouraging sedentary life style and long screen viewing and education on healthy food options in school are all directed towards lowering Body Fat \%. Therefore our study suggests along with BMI, Body Fat \% should be measured to predict or diagnose overweight and obesity especially in school children as the BF \% can be calculated/ measured easily and reliably by simple BIA.

\section{Conflicts of interest: None}

\section{REFERENCES}

[1]. Popkin BM, Adair LS, Ng SW. Global nutrition transition and the pandemic of obesity in developing countries. Nutr Rev 2012;70:3 21.

[2]. R Khadgwat, R K Marwaha, N Tandon, N Mehan, AD Upadhyay, A Sastry and K Bhadra. Percentage of body fat in apparently healthy school children from northern India, Indian paediatrics 2013;50:859866.

[3]. de Onis M, Blossner M \& Borghi E. Global prevalence and trends of overweight and obesity among preschool children. Am J Clin Nutr.2010;92:125764.

[4]. Amit Kumar Mishra, Himansu Prasad Acharya, Ram Chandra Giri. Prevalence of obesity among school children aged 10-12 years in Sambalpur. Int J Med Sci public Health 2015;4(10):1366-1368.
[5]. Cotes JE, chin DJ, Miller MR, Lung Function, physiology Measurement and application in medicine, Blackwell,6 $6^{\text {th }}$ edition.2006; Chapter4:37.

[6]. James WPT, Ralph A. New understanding in obesity research. Proc Nutr Soc 1999;58:385-393.

[7]. Goran MI, Driscoll P, Johnson R, Nagy TR, Hunter G. Cross-calibration of body composition techniques against dual-energy $X$ ray absorptiometry in young Children. Am J Clin Nutr.1996;63:299-305.

[8]. Sanghamitra Pati, Mohammad Akhtar Hussain, Abhimanyu Singh, Chauhan. Prevalence and correlates of childhood obesity in suburban area of Odisha: A cross sectional study. Epidemiology Biostatistics and Public Health- 2014;11(3):1-6.

[9]. Sharon A Plowman, Denise L. Smith. Exercise Physiology, For health, fitness, and performance. $3^{\text {rd }}$ edition, 2004.

[10]. Satyajit Bagudai, Pranati Nanda, Satyanath Reddy Kodidala. Prevalence of Obesity and hypertension in adolescent school going children of Berhampur, Odisha, India. International journal of physiotherapy and research 2014;2(6):777-780.

How to cite this article:

Biswabara Rout, Snigdha Prava Mishra, Tapas Ranjan Behera . STUDY OF BMI AND BODY FAT\% IN ADOLESCENT BOYS. Int J Physiother Res 2017;5(3):2035-2038. DOI: 10.16965/ijpr.2017.134 